\author{
Ангелов Г.В. \\ доктор философии, профессор \\ E-mail: sociologia.kafedra@mail.ru \\ Черкасский A.B. \\ кандидат исторических наук, доцент \\ кафедра социологии, фрилософии и права \\ Одесская национальная академия пищевых технологий \\ ул. Канатная, 112, г. Одесса, Украина, 65039 \\ E-mail: sociologia.kafedra@mail.ru
}

\title{
ПСИХОЛОГИЧЕСКИЕ ОСОБЕННОСТИ ФУНКЦИОНИРОВАНИЯ УПРАВЛЕНЧЕСКИХ КОМАНД НА ПРЕДПРИЯТИЯХ ПИЩЕВОЙ ОТРАСЛИ
}

В статье рассматриваются психологические механизмы деятельности управленческих команд, основные этапы их становления и развития. Особое внимание уделено особенностям их функционирования на предприятиях пищевой отрасли, подчёркивается их взаимосвязь с общими управленческими инновациями, которые нацелены на повышение стабильности, эффективности и конкурентоспособности предприятия.

Ключевые слова: управленческие команды, социальная идентификация, социальные репрезентации, групповая сплочённость, неформальная структура, управленческие инновации, социальная ответственность.

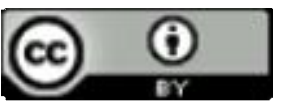

This work is licensed under a Creative Commons Attribution 4.0 International License http://creativecommons.org/licenses/by/4.0/
Постановка проблемы и ее связь с важными научными и практическими заданиями. Развитие современных технологий и социальноэкономических отношений находят все большее отражение в изменении концепций структуры работы в организациях. В последние десятилетия в сфере производственной и организационной растет потребность в кооперации и технологические процессы требуют интеграции, а обмен информации приобретает глобальный характер. В связи с этим в общественной практике и в науке значительно вырос интерес к изучению групп, командных форм работы.

Сегодня, в эпоху сильнейшей мировой конкуренции и появлением новых технологий именно командная работа играет ведущую роль в достижении ощутимых организационных результатов, способствует поддержке конкурентных преимуществ компаний и их эффективности. Современным организациям нужны сотрудники, которые качественно выполняют работу в условиях организационных изменений, помогают это делать другим, быстро создают атмосферу сотрудничества[2].

В связи с развитием методов управления и внедрением управленческих команд особенную актуальность приобретают исследования, направленные на выявление психологических условий и факторов, при которых возможны и эффективны новые коллективные формы управления и их взаимодействие.

Анализ последних публикаций по проблеме. Проблема деятельности команд и особенностей их формирования в современных организациях нашла отражение в исследованиях таких ученых, как М. Белбин, Д. А. Веттен, М. Геллерт, Р.Кропп, П. Мучинськи, К. Новак, Г. Паркер, Х. М. Пейро, М. А. Уэст, К. Фопель, Т. Грабенко, А. П. Ерошинин, Г. Сартан и др. Некоторые исследователи рассматривали отдельные аспекты функционирования команд. Так, например А.А. Авдеев изучал технологии формирования команды, Е.П. Валь проблемы эффективной мотивации персонала, Т.П. Галкина вопросы группового управления, Т.Д. Зинкевич-Евстигнеева автор тренинговых программ по деловым коммуникациям, командообразованию, инновационному менеджменту. К сожалению, менее изученными оказались проблемы формирования и развития команд в отдельных отраслях промышленности и производства.

Формулирование целей исследования. Раскрыть основные психологические механизмы деятельности управленческих команд и особенности их функционирования на предприятиях пищевой промышленности Украины.

Изложение основных результатов и их обоснование. В современном мире происхолит всё большая гуманизация и психологизация менеджмента, которая проявляется в направленности на самоценость личности, на всестороннее развитие её прав и свобод. Изменение господствующего во времена индустриализма метода в парадигме современного менеджмента из технологического на психологический 
детерминизм обусловило существенное изменение взгляда на понятие эффективности деятельности организации. Рядом с традиционным понятием «экономическая эффективность» появилось другое - «социальная эффективность»[1].

В самом общем виде управленческая команда представляет собой специфическую общность специалистов, объединенных посредством формальных и неформальных отношений, способную вырабатывать эффективные управленческие решения. Именно команда способна синтезировать и создавать такие собственные качества, которые позволяют решать сложные задачи. В тех случаях, когда усилия работников взаимозависимы, они действуют как специальная команда, которая должна решать профессиональные задания и достичь высокого уровня взаимодействия. Основная цель формирования команды при этом заключается в создании в рабочих группах возможностей лучше выполнять работу и повышать ее результативность[6]. Поскольку труд членов команды направлен на достижение определенной цели, то все ее члены привержены единой миссии и несут коллективную ответственность[4].

В процессе своего становления команда проходит последовательно 4 стадии:

1.Стадия рабочей группы. На данной стадии происходит формирование группы. Цели ещё не ясны, выполнятся мало работы.

2.Стадия псевдокоманды. На данном этапе проявляются конфликтные ситуации, соперничество за лидерство, достаточно низкая производительность.

3.Стадия потенциальной команды. На данном этапе происходит выработка норм и правил продуктивного поведения, появляется чувство командной компетентности и принадлежности, удовольствие от совместной работы, производительность от средней до высокой.

4. Стадия реальной команды. На данном этапе работоспособность членов команды находится на высоком уровне, понимание друг друга без слов, постоянный личностный рост, высокая степень производительности.

В современной практике управления существует целый ряд критериев для определения эффективности работы команды. Наиболее значимыми, на наш взгляд, являются психологические критерии:

- удовлетворенность членов команды различными аспектами членства в ней (отношениями с коллегами и руководителями, условиями труда, заработной платой и т.д.);

- мотивация членов команды (желание трудиться и сохранить членство в коллективе);

- авторитет руководителя в коллективе;

- самооценка команды (она касается целого ряда важных ее характеристик и представляет собой некий общий итог успешности ее функционирования) [5, C.119].

В настоящее время исследователи выделяют ряд первостепенных психологических механизмов, которые пронизывают весь процесс командной работы [7]. Два механизма, которые особенно полезны для понимания психологии командной работы, известны как социальная идентификация и социальные репрезентации. В самом широком понимании социальная идентификация - это склонность человека видеть мир в понятиях «мы» - «они». Принадлежность к команде позволяет людям чувствовать себя поособенному: осознавать, что их группа непохожа на другие и компетентна в большей степени, чем остальные, или в чем-то превосходит их. Такое осознание собственной «особенности» и является социальной идентификацией.

Социальные репрезентации - это общие идеи и убеждения, присущие всей команде. Теория социальной репрезентации была разработана французским психологом С.Московичи. Это теория об общих убеждениях, разделяемых группами и культурами, и о том, какие функции они выполняют в повседневной жизни организации [10].

Рассматривая особенности деятельности управленческих команд в пищевой отрасли, необходимо прежде всего отметить их определённую специфическую автономию при подготовке и принятии решений. В командах происходят одновременно процессы управления и обучения управлению. Члены команды, как правило, владеют несколькими профессиями, имеют высокую квалификацию. Это позволяет обеспечивать постоянный рост эффективности труда, снижать потребность в узких специалистах и повышать степень удовлетворённости трудом.

Следует отметить, что такая неформальная организация позволяет осуществлять управление деятельностью своих членов с очень высокой эффективностью. В командах существует своя неформальная структура, которая характеризуется своими целями, базовыми ценностями, нормами, правилами, координацией деятельности, чёткой системой контроля, собственной системой коммуникаций, своей ярко выраженной организационной культурой, системой мотивации и т.п.

Другой характерной особенностью командной работы в данной отрасли является чувство общности коллектива, групповой сплочённости, которая определяется как «... идейное, моральное, интеллектуальное, эмоциональное и волевое единство его членов, которое развивается на основе такой объективной характеристики, как организационное единство» [8, С.966]. В командах хорошо подобран и сбалансирован состав работников в зависимости от необходимых ролей, поэтому члены команд, будучи взаимосовместимыми, хорошо сотрудничают друг с другом и имеют высокую степень удовлетворённости от совместной деятельности.

В управленческую команду подбираются, как правило, люди, обладающие не только профессиональными знаниями, но и навыками межличностного общения и взаимодействия (взаимовлияния, восприятия друг друга и др.)[9]. Это позволяет решать любые поставленные задачи творчески, креативно, что делает команду, по сути, «мозговым центром» организации. Такие качества, как надёжность, порядочность, честность, высокое чувство выполняемого дол- 
га - вот что должно всё более зримо отличать членов данных команд, ведь эффективность производства продуктов питания зависит от сложившейся гармонии людей, трудящихся в системе «Поле-стол». Кроме того, борьба за достойное выживание человека как социобиологического вида напрямую зависит не только от профессионализма людей, работающих в пищевой отрасли, но и от их нравственных устоев, от их глубокого понимания особой ответственности перед каждым, кто доверил им свою судьбу. Формирование именно такого нравственно-психологического климата в современных управленческих командах пищевой отрасли и будет, как нам кажется, гарантом этого.

Залогом успешной деятельности предприятий пищевой промышленности в долгосрочной перспективе является их способность изменяться в соответствии с переменчивыми рыночными условиями с помощью управленческих механизмов. В качестве таких механизмов выступают управленческие инновации в виде цепи взаимоувязанных и сознательно инициированных изменений, связанных с качественным реформированием управленческого блока и нацеленные на повышение стабильности, эффективности и конкурентоспособности предприятия[3].

И важную роль в этих управленческих инновациях, безусловно играют эффективно организованные управленческие команды, главным критерием деятельности которых будет качество выпускаемой продукции пищевой отрасли Украины.

Выводы и перспективы дальнейших исследований. Команды обладают огромным потенциалом, который они могут привнести в жизнь современных организаций. Успешно работающие команды поощряют гибкость, вовлечённость, эффективность.
Два психологических механизма - социальная идентификация и социальные репрезентации являются активными процессами, лежащими в основе успешной командной работы. Социальная идентификация связана с принадлежностью к группе, а социальная репрезентация связана с усвоением всеми членами группы общих фундаментальных убеждений.

Важной характерной особенностью командной работы является чувство групповой сплочённости, которое позволяет творчески решать любые задачи и приносит высокую удовлетворённость от совместной деятельности.

В настоящее время проводится активная работа по внедрению в практику инновационных санитарно-гигиенических норм, новых технологий, повышающих эффективность ключевых производственных процессов, всё предметнее становится воспитание персонала, направленное на глубоковыверенные, взвешенные подходы к различным новшествам с учётом их возможных долгосрочных последствий, всё большее внимание уделяется актуальным вопросам логистики, расширению и укреплению действенной связи с многопрофильными отечественными и зарубежными центрами и т. д.

Но, пожалуй, главное, что формируют управленческие команды у членов трудовых коллективов отрасли - высокую социальную ответственность за качество изготовляемой продукции, обеспечивающее продовольственную безопасность нашего народа. Сейчас в этом главном деле имеются и определённые успехи и серьёзные недочёты, но то, что это направление становится доминирующим на всё большем количестве предприятий страны, свидетельствует о том, что мы в современном управлении выбрали верное звено, вытянув которое, нам удастся вытянуть и всю цепь существующих ныне проблем.

\section{Литература}

1. Андрущенко В.П. Організоване суспільство. Проблема організації та суспільної самоорганізації в період радикальних трансформацій в Україні на рубежі століть. Досвід соціально-філософського аналізу / В.П. Андрущенко. - К.: Генеза, 2006. - 546с.

2. Етичний фактор в сфері праці і соціального управління / [Гулавський В.Т., Козак К.Б., Черкаський А.В. та ін.] ; під заг. ред. Г.В. Ангєлова. - Одеса: КП ОМД, 2010. - 596 с.

3. Давлєтбаєва Н. Упровадження управлінських інновацій на підприємствах харчової промисловості як запорука підвищення їх конкурентоспроможності / Н. Давлєтбаєва // Галицький економічний вісник, - Т.: ТНТУ, 2015. -Т. 48, № 1. - С. 48-54.

4. Дафт Ричард Л. Менеджмент / Ричард Л.Дафт; пер. с англ. В.Вольского, С.Жильцова, Д.Раевского. СПб.: Питер, 2000. - 562 с.

5. Лачинина Т. Команда в организации: эффективность совместной деятельности / Т. Лачинина // Проблемы теории и практики управления. 2007. - № 7. - С.119 - 126. $448 \mathrm{c}$.

6. Ньюстром Дж.В. Организационное поведение / Дж.В.Ньюстром, К.Дэвис. - СПб.: Питер-Юг, 2000. -

7. Хейз Н. Успех один на всех: основные аспекты эффективного руководства командой / Н.Хейз; пер. с англ. - Днепропетровск: Баланс Бизнес Букс, 2005. - 240с.

8. Черкаський А.В. Соціально-психологічні особливості групової згуртованості та їх вплив на ефективність спільної діяльності / А.В. Черкаський // Актуальні проблеми психології : Збірник наукових праць Інституту психології імені Г.С. Костюка НАПН України. - 2012. - Т. Х, Вип.23. - С. 966-974.

9. Черкаський А.В. Соціально-психологічні особливості спілкування в процесі спільної групової діяльності / А.В. Черкаський // Актуальні проблеми психології: Збірник наукових праць Інституту психології імені Г.С. Костюка НАПН України. - 2013. - Т. Х, Вип. 25. - С. 548-556. 
10. Moscovici, S. (1984) The phenomenon of social representations, in Social Representations (eds. R.M. Farr and S. Moscovici ) Cambridge University Press, Cambridge.

Статья поступила 24.12.2016 Статья принята в печать 12.01.2017 Доступно в сети Internet 31.03.2017

\author{
Ангелов Г.В. \\ доктор фрілософії, профресор \\ E-mail: sociologia.kafedra@mail.ru \\ Черкаський A.B. \\ кандидат історичних наук, доцент \\ кафедра соціології, фрілософії і права \\ Одеська національна академія харчових технологій \\ вул. Канатна, 112, м. Одеса, Україна, 65039 \\ E-mail: sociologia.kafedra@mail.ru
}

\title{
ПСИХОЛОГІЧНІ ОСОБЛИВОСТІ ФУНКЦІОНУВАННЯ УПРАВЛІНСЬКИХ КОМАНД НА ПІДПРИЄМСТВАХ ХАРЧОВОЇ ГАЛУЗІ.
}

У статті розглядаються психологічні механізми діяльності управлінських команд, основні етапи їх становлення і розвитку. Особлива увага приділена особливостям їх функціонування на підприємствах харчової галузі, підкреслюється їх взаємозв'язок із загальними управлінськими інноваціями, які націлені на підвищення стабільності, ефективності і конкурентоспроможності підприємства.

У найзагальнішому вигляді управлінська команда $€$ специфічною спільністю фрахівців, об'єднаних за допомогою формальних і неформальних стосунків, здатну виробляти ефективні управлінські рішення. Саме команда здатна синтезувати і створювати такі власні якості, які дозволяють вирішувати складні завдання.

Два механізми, які особливо корисні для розуміння психології командної роботи, відомі як соціальна ідентифікація і соціальні репрезентації.Соціальна ідентифікація пов'язана з приналежністю до групи, а соціальна репрезентація пов'язана з прийняттям усіма членами групи загальних фундаментальних переконань. В управлінську команду підбираються, як правило, люди, що мають не лише професійні знання, але і навички міжособового спілкування і взаємодії. У командах, як правило, добре підібраний і збалансований склад працівників залежно від необхідних ролей, тому члени команд, будучи взаємосумісними, добре співпрацюють один з одним і мають високу міру задоволеності від спільної діяльності. Запорукою успішної діяльності підприємств харчової промисловості в довгостроковій перспективі $€$ їх здатність змінюватися відповідно до мінливих ринкових умов за допомогою управлінських механізмів. Такими механізмами виступають управлінські інновації у вигляді ланцюга взаємопов'язаних і свідомо ініційованих змін, пов'язаних з якісним реформуванням управлінського блоку і націлені на підвищення стабільності, ефективності і конкурентоспроможності підприємства.

Ключові слова: управлінські команди, соціальна ідентифікація, соціальні репрезентації, групова згуртованість, неформальна структура, управлінські інновації, соціальна відповідальність.

Angelov G.

Doctor of Philosophy, Professor

E-mail: sociologia.kafedra@mail.ru

Cherkassky A.

PhD, Associate Professor

Department of the Sociology, Philosophy and Law

Odessa National Academy of Food Technologies

Kanatna Str., 112, Odessa, Ukraine, 65039

E-mail: sociologia.kafedra@mail.ru

\section{PSYCHOLOGICAL FEATURES OF THE FUNCTIONING OF THE MANAGEMENT TEAMS IN THE FOOD INDUSTRY}

The article deals with the psychological mechanisms of management teams activity, the main stages of their formation and development. Particular attention is paid to the peculiarities of their functioning in the 
food industry, their relationship with the general management innovations, which are aimed at increasing the stability, efficiency and the competitiveness of the enterprises, have been underlined.

In the most general form of the management team is a specific community of professionals, united by means of formal and informal relationships, which is able to develop effective management decisions. This team is able to synthesize and create such personal qualities that make it possible to solve complex problems.

Two mechanisms that are particularly useful for understanding the team work psychology known as social identity and social representation. Social identification is associated with belonging to a group, but a social representation is associated with the adoption of the shared fundamental beliefs by all the members of the group. The management team is selected, as a rule, from people who have not only technical expertise, but also interpersonal skills and interactions. The teams are usually well matched and balanced composition of workers, depending on the required roles, so the team members cooperate well with each other and have a high degree of satisfaction from the joint venture.

The key to the success of the food industry in the long term is their ability to change according to the changeable market conditions with the help of management tools. As these mechanisms are the managerial innovations in the form of a chain of interconnected and consciously initiated changes related to the reform of quality management unit and aimed at improving the stability, efficiency and competitiveness of the enterprise.

Keywords: management teams, social identification, social representation, group cohesion, informal structure, management innovation, social responsibility.

\section{References}

1. Andrushchenko, V. P. (2006). Orhanizovane suspilstvo. Problema orhanizatsii ta suspilnoi samoorhanizatsii v period radykalnykh transformatsii v Ukraini na rubezhi stolit. Dosvid sotsialno-filosofskoho analizu. K.: Geneza.

2. Anhielov, H. V. (2010). Etychnyi faktor v sferi pratsi i sotsialnoho upravlinnia . Odesa: KP OMD.

3. Davlietbaieva , N. (2015). Uprovadzhennia upravlinskykh innovatsii na pidpryiemstvakh kharchovoi promyslovosti yak zaporuka pidvyshchennia yikh konkurentospromozhnosti . Halytskyi ekonomichnyi visnyk, 1(48), 4854.

4. Rychard, D. L. (2000). Menedzhment . Pyter: SPb.

5. Lachynyna , T. (2007). Komanda v orhanyzatsyy: эffektyvnost sovmestnoi deiatelnosty. Problemb teoryy y praktyky upravlenyia, 7, 119-126.

6. Niustrom, Dzh. V. (2000). Orhanyzatsyonnoe povedenye . Pyter-Iuh: SPb.

7. Kheiz , N. (2005). Uspekh odyn na vsekh: osnovnыe aspektы эffektyvnoho rukovodstva komandoi. Dnepropetrovsk: Balans Byznes Buks.

8. Cherkaskyi, A. V. (2012). Sotsialno-psykholohichni osoblyvosti hrupovoi zghurtovanosti ta yikh vplyv na efektyvnist spilnoi diialnosti. Aktualni problemy psykholohii : Zbirnyk naukovykh prats Instytutu psykholohii imeni H.S. Kostiuka NAPN Ukrainy, 23, 966-974.

9. Cherkaskyi , A. V. (2013). Sotsialno-psykholohichni osoblyvosti spilkuvannia v protsesi spilnoi hrupovoi diialnosti . Aktualni problemy psykholohii: Zbirnyk naukovykh prats Instytutu psykholohii imeni H.S. Kostiuka NAPN Ukrainy., 25, 548-556.

10. Moscovici, S. (1984). The phenomenon of social representations, in Social Representations . Cambridge: Cambridge University Press.

Received 24 December 2016

Approved 12 January 2017

Available in Internet 31.03.2017 